\title{
BLANCHOT, PARADOXO PLURAL *
}

\author{
Mauricio Salles de Vasconcelos $^{* *}$
}

Resumo: Maurice Blanchot compreende a literatura como um espaço diferencial, paradoxal margem onde o campo do conbecimento é redefinido. Via plural de teoria e narrativa, a escrita blanchotiana estabelece com escritores e filósofos uma conversa infinita, uma outra forma de leitura e saber; concebe um livro por vir.

O pensamento de Blanchot se constitui de um procedimento próprio de escrita, montado entre a incursão na linguagem do texto literário e o distanciamento de quem a disseca, numa tática de análise erguida sobre núcleos conceituais precisos, originados, porém, de uma adesão ao universo estético contemplado. É do espaço construído pela literatura que o filósofo parte, mantendo-o fora de qualquer ordem a não ser aquela proveniente da espacialização, da repetição de uma abordagem - trata-se, na verdade, de uma voz interior à escrita, disposta, porém, no plano de um "longínquo interior" (como diz um poema de Michaux) - existente apenas nessa mar-

\footnotetext{
- Recebido para publicação em março de 2002.

- Professor do Departamento de Semiótica e Teoria da Literatura da Faculdade de Letras da UFMG.
} 
gem. O que caracteriza um saber não sedimentado para além da "orla exígua (...) que nos preserva da pressão cega" da distância das coisas (BLANCHOT, 1987: 256).

$\mathrm{O}$ encontro com esse pensamento requer um certo grau de convivência, de uma certa iniciação até, pois encerra um primeiro e básico paradoxo - o fato da crítica de Blanchot estar tão próxima da escrita de modo a melhor atentar para o funcionamento das redes culturais, temporais, em que a literatura se dispõe e a partir das quais afirma seu lugar de fora. Lugar que subsiste sob a tensão de seu próprio desaparecimento na fronteira dos saberes (ou a morte, que marca o percurso da criação literária na modernidade e, também, assinala:a configuração do campo das ciências humanas, no ver de Foucault).

Desde que Blanchot incorporou à sua leitura filosófica da literatura a noção de il y a (bá), exposta por Levinas em De l'existence à l'existant (1947), o autor de La part du feu (1949) pôde dispor de um referencial para a compreensão do fato estético não mais centrado na dimensão ontológica do ser de linguagem heideggeriano (uma referência indesviável àquela época). Não por acaso, Levinas desenvolve, no livro citado, um contraponto ao filósofo de Ser e tempo, tendo como exemplo Thomas L'obscur, a primeira narrativa (e primeiro livro) produzida por Blanchot.

O horror da noite, enquanto experiência do há, não nos revela (...) um perigo de morte, nem mesmo um perigo de dor (...) O puro nada da angústia heideggeriana não constitui o há (...) Opomos, então, o horror da noite, "o silêncio e o horror das trevas" à angústia heideggeriana: o medo de ser ao medo do nada. Enquanto a angústia, em Heidegger, cumpre o "ser para a morte" (...) o horror 
da noite "sem saída" e "sem resposta" é a existência irremissível. (LEVINAS, 1947: 102)

Com base em Évolution créatrice, de Bergson, o pensador extrai elementos que se complementam com a leitura de Thomas l'obscur, e por sua vez já contêm os desdobramentos daquilo que viria a se configurar como o pensamento blanchotiano, muito particularmente o que se firma a partir de ensaios como "A literatura e o direito à morte", incluído em La part du feu:

(...) a negação - que, segundo Bergson, possui um sentido positivo enquanto movimento do espíritọ que rejeita um ser para pensar um outro - aplicada à totalidade do ser, não teria mais sentido. Negar a totalidade do ser é, para a consciência, lançar-se numa espécie de obscuridade ou, ao menos, é deixar permanecê-la enquanto funcionamento, enquanto consciência dessa obscuridade. A negação total seria, então, impossível, e pensar o nada, uma ilusão. Mas a crítica bergsoniana do nada não visa mais do que à necessidade de um estar sendo, de "alguma coisa" que existe. Ele aborda o ser, em toda sua crítica como um "sendo", e chega a um "sendo" residual. (...) O fato de ser um conteúdo obtido pela negação de todo conteúdo, permanece sem consideração. A obscuridade - enquanto presença de uma ausência não é um conteúdo puramente presente. Não se trata de uma "qualquer coisa" que permanece, mas da atmofera mesma da presença, que pode aparecer certamente depois dessa visão como um conteúdo, mas que, originalmente, é o evento impessoal, a-substantivo da noite e do há. (Op.cit.: 103-104). 
Essa longa citação tem sua razão, entre outros Motivs, por deixar à mostra os antecedentes essenciais do vínculo que pode se estabelecer entre Blanchot e Deleuze, por exemplo, como é o caso de Bergson, um dos pontos nucleares do que definiu Michael Hardt como a aprendizagem deleuziana pela filosofia. Mas se explica, também, pelo que faz cruzar com o itinerário do escritor de literatura que é Blanchot, autor de Thomas l'obscur.

É o que se nota na abordagem de Levinas, quando da contraproposição a Heidegger, ao referir-se à narrativa como a própria descrição do il y $a$. De acordo com sua visão, Blanchot já encaminhava todos os índices da ausência, da noite, da dissolução do sujeito, do borror de ser, numa condução da negatividade e do nada, explorados pela ontologia heideggeriana e pelo existencialismo (considerando-se o contexto dos anos 40 do século $\mathrm{XX}$ ), para um plano situado fora de sua incorporação em um projeto metafísico e mesmo da ordenação dialética do pensamento.

"A literatura e o direito à morte" pode ser compreendido como um ensaio de passagem - o ponto em que o debate sobre as possibilidades de conhecimento do lugar e da prática da literatura se articula como construção inconfundível de um pensamento e de uma escrita materializados no decorrer de décadas. Para a realização do texto, Blanchot parte de um repertório crítico e filosófico hegemônico, exposto em exaustiva indagação, mas nele se centraliza a avaliação do pensamento hegeliano, tomado do prisma atualizador oferecido pelo livro de Alexandre Kojève, Introduction à la lecture de Hegel, publicado na França em 1947 (o mesmo ano, aliás, de L'existence à l'existant, de Levinas).

$O$ ensaio escrito sob o influxo da leitura reveladora de Hegel, empreendida por Kojève, debate-se principalmente com a ênfase dada na consubstanciação de um pensamento da morte 
(o que, na prática hegeliana, faz fundar a materialidade no instante em que o Sujeito ou o Espírito é reconquistado em si mesmo pela via negativa da criação, proveniente da consciếncia de ser mortal). Blanchot atenta exatamente para a presença mortal quando do corte feito com o Espírito, com a suposta transcendência contida neste plano, tendo-se em vista a demolição hegeliana do Cristianismo e a consciência de finitude, de mortalidade, originária de um traço negativo de base por que passam pensamento, ser e criação.

$\mathrm{O}$ autor de La part du feu retém de Introduction à la lecture de Hegel os princípios de finitude e mortalidade para dispô-los não mais como fundamento da consciência geradora da ação que conduz à unidade a se reconstituir no mundo, na História, pela estratégia negativa e salvaguardadora de um sujeito constituído em lugar da substância (Idéia, entre os gregos, de Ser puramente natural, destituído de individualidade, história e negatividade).

Em vez da contraproposta, ainda substancialista, de um fundamento no sujeito, concebido, então, por uma negatividade/contrariedade básica, o leitor de Hegel e Kojève, que é Blanchot, nesse ensaio fundante da atividade e da dicção ensaísticas do jovem crítico no espaço do livro, compactua-se com o que induz a escrita de literatura a um saber extremo. Um saber posto em diálogo, entre outras possibilidades, com o existencialismo de Sartre (presença visível em "A literatura e o direito à morte", tendo aí discutidas as teses desenvolvidas em Qu'est-ce que la littérature?, uma produção também publicada em 1947), com verdadeiros emblemas da filosofia ocidental moderna (caso de Hegel), guiando-se por um direcionamento ainda mais contrário àquele proposto pelo pensamento hegeliano, de modo a não controlar o movimento da contradição, o potencial da diferença. 
Deixando de compreender a produção de literatura como projeto de materialização na história, no mundo, na perspectiva do trabalho e da luz esclarecedora do dia, considerado como elemento constituidor da razão, do centramento do sujeito/objeto do conhecimento, o jovem crítico constata um poder próprio, poder de faltar com a verdade - a força que impelia Kafka a ser escritor: "Esse talvez seja um enigma indecifrável, mas, se o é, o mistério vem então do direito da literatura a atribuir indiferentemente a cada um de seus momentos e a cada um de seus resultados, o sinal negativo ou positivo." (BLANCHOT, 1997: 327)

Através do debate - marcado por interrogações e variantes conceituais intermitentes, intermináveis - com o pensamento hegeliano, o estudioso percebe que a literatura trabalha no mundo - em vez de ser um dos trabalhos do mundo -, enquanto este "considera seu trabalho um jogo nulo e perigoso" (BLANCHOT, 1997: 327). O veio aqui tomado é o de um aprendizado pela literatura, um "conhecimento" não circunstancializado, nada apazigüado com um trabalho de negação recon" ciliador do vínculo com o todo e o mundo pela criação.

Kafka é, no ver do autor de "A literatura e o direito à morte", uma referência crucial para o norteamento de uma indagação que não pode deixar de submeter a uma desmontagem critérios vigentes de verdade, linguagem, negatividade, constantes do horizonte problemático oferecido à atividade literária. Interrogações contínuas, um processo aberto sob o signo do negativo, da morte, sem mais suporte e destinação dialéticos. Não há todo a ser reafirmado ou ao qual se possa remitir. Não há unidade ou qualquer pacto com a hora do mundo, no espaço produzido pelos livros dos criadores de literatura. Dentro dessa compreensão, a literatura deixa de ser o momento de recriação - "o maior fermento da história" (Ibid.) - ou de ajuda na conscientização desse todo. 
Indeferida pela história, a literatura joga por um outro lado. Se não está realmente no mundo, trabalhando para fazer o mundo, é porque, por sua falta de ser (de realidade inteligível), ela se relaciona com a existência ainda desumana. Sim, ela reconhece, existe em sua natureza um deslizamento estranho entre ser e não ser, presença, ausência, realidade e irrealidade (...) Ela năo é explicação, nem pura compreensão, pois o inexplicável está nela. E expressa sem expressar, oferecendo sua linguagem ao que se murmura na ausência da palavra. A literatura aparece então ligada à estranheza da existência que o ser rejeitou e que escapa a qualquer categoria. O escritor se sente presa de uma força impessoal que não o deixa viver ou morrer (...) (Op.cit.: 326)

Ainda que tomados pelo teor destrutivo, negativo de suas produções, autores como Kafka (um dos guias não só do ensaio, mas de todo o livro e daqueles que lhe sucederam) não encerrariam a voltagem tumultuosa, intempestiva da escrita na órbita da contraposição dialética. Pois esta, concebida como possível patamar diferencial do processo centrado em uma primeira pessoa constituída e cognoscente, acaba por promover tão somente a assunção da unidade conciliadora, recortada do múltiplo. Só restitui o uno - o igual, reforçado pela contradição harmonizadora, pela relativização da diferença.

Em Blanchot, desde esse preliminar e aguerrido ensaio de 1955, é a ausência que aflora, não mais contida no jogo mecânico, autoregulado de ausência/presença, próprio do que se pode chamar de uma metafísica da linguagem, presa da construção dualista do pensamento. Não se trata mais de compor um processo com princípio e fim circunscritos a um sujeito esclarecedor do vínculo problemático com o que lhe é adverso. Nem juízo crítico da parte do ensaísta (ele não realiza, de fato, 
uma análise ou interpretação literária). Não há lugar para o porta-voz, o colecionador/classificador estético, o juiz do Livro (ou guardião da Noite).

Estando mais em cognição do que referencializada a um conhecimento central e final sobre si e o mundo, tal como sucede no decorrer do movimento regenerador da dialética, essa pessóa primeira do pensamento não subsiste mais como representação opositiva ao nada e à ausência, elementos de que Blanchot se nutre, nesse momento, que é, também de fim do existencialismo. O que importa ressaltar é a permanência de um processo - tal como lida nos escritos de Levinas - para fora do esquadro de uma síntese superior do ser, seja em nome da autenticidade (Heidegger) seja em nome da história (Hegel, Sartre).

Mostra-se mais visível o contraponto feito pelo pensador francês a Hegel, quando são observadas as considerações deste acerca do nada, da noite e da criação:

O bomem é essa noite, esse Nada vazio, que contém tudo em sua simplicidade indivisa (Einfachheit): a riqueza de um número infinito de representações, imagens, as quais nenbuma lhe vem ao espirito, ou que não estão enquanto tais realmente-presentes (gegenwartig). $\dot{E}$ a noite, a interioridade-ou-intimidade (Innre) da Natureza, que existe aqui: [o] Eu-pessoal puro. Nas representações fantasmagóricas, é noite ao redor (...) é a noite do mundo que se apresenta (hängt antgegen) [então] a nós. Potência (Macht) de extrair dessa noite as imagens ou deixá-las cair: posição autônoma (Selbssetzen) [quer dizer criação livre], consciência interior, Ação (Tun). É essa noite que se retira a entidade-existente-como-umser dado (das Seiende); mas o movimento [dialético] dessa potência é igualmente posta." (Apud KOJÈVE, 1947: 575) 
É a ausência, porém, que aflora, em Blanchot, e não a noite como espaço íntimo e recolhedor. Nada mais pode ser preenchido no embate do pensamento e da escrita com a noite - não de seu fundo (origem negativa do trabalho, da história, do humano) -, considerada, então, em toda a sua exterioridade.

Em nada pode repousar o confronto do autor de O livro por vir com o pano-de-fundo a partir do qual se representa 0 automovimento resguardador do pensamento, tal como Kojève formula, desdobrando o trecho citado de Hegel:

O movimento dialético da potência que mantém no Ser o Nada que é o Homem - é a História. E esssa potência se realiza em si mesma e se manifesta enquanto Ação negativa ou criativa: Ação negativa do que é dado - o Homem em si mesmo -, ou ação da Luta que criou o homem histórico. (Ibid.)

A Noite - entidade orgânica do romantismo; em filosofia e arte - não se engendra para Blanchot como um lugar prévio do sujeito esclarecedor do conhecimento. Deixa de ocorrer, assim, a substancialização do nada (figurado em Noite) a que o sujeito se oporia, ao criar sua gênese e linguagem (construção dual) no campo do ser, do pensar e do acontecer no tempo. Desponta a complexa atividade de uma individuação sem substância, impessoal, afirmada, ao infinito, desse locus (não formulado como um adentrar, um dentro) da desmesura, compreendido em uma radical não-transcendência.

Força impessoal (BLANCHOT, 1997: 326) que não se deixa viver ou morrer, como diz o ensaísta em "Literatura e o direito à morte", apreendendo, em De l'existence à l'existant, de Levinas, tudo o que conduz à experimentação do estado de neutralidade - o estado do nada sem incorrer na substancia- 
lização do nada, mas a seu vazio pleno, sem atribuição e juízo como dado inelutável de uma condição sempre alterna, situada para além de si e do horizonte demarcado para o homem histórico. Como resume Leslie Hill, em comentário a Levinas: "o ser torna-se inseparável de sua ausência ilimitada e da impossibilidade de fundação" (Op.cit.: 63).

i Se o pensamento de Levinas já indicava uma direção contrária à autentificação do ser proposta por Heidegger, no caso de Blanchot ocorre uma mudança, ainda mais pronunciada, em relação ao filósofo de Ser e tempo, na trilha que segue seu trabalho em torno da idéia de morte, tomada como fundamento das marchas e contramarchas da lógica ocidental. De acordo com a leitura feita por Derrida, em Demeure, livro no qual volta a se concentrar sobre Blanchot (depois de Parages, de 1986), e em especial sobre um dos seus últimos escritos - mescla de narrativa, testemunho e ensaio, onde ele conta sua súbita libertação após ameaça de fuzilamento pelos nazistas, num face a face com o fim, diante das armas de guerra - L'instant de ma mort (1994):

Afirmando uma morte que, por ser insubstituível, já que única, não é jamais "individual", Blanchot avança aqui em relação a uma proposição inquietadora até esse Jemeinigkeit, esse "cada vez meu" que caracterizaria de maneira essencial, segundo Heidegger, um Dasein, anunciado a si mesmo, em seu próprio ser-para-a-morte. (1998: 63)

Erguida sobre a formulação de um paradoxo, a idéia de morte, segundo o ensaísta e narrador, deixa de sofrer a apropriação onipresente da individualidade. O sentido de destinação contido na morte, a súmula que representa o desenlace final, 
são desarticulados ao longo do trajeto de Blanchot, tendo como base a sistematização de escrita e pensamento (na verdade, um projeto filosófico gestado pela leitura de textos de literatura) proposta no último ensaio de La part du feu.

Duplo paradoxo - apesar de manifestado numa individuação, o trabalho mortal é experiência comum, extensiva a qualquer-um, o que encaminha sua realidade e realização para fora de uma problemática eminentemente ontológica (nos termos em que para Heidegger a possessividade/particularidade do processo se anunciava como um desígnio para ser). Este se compreende, então, como construção integrante de um plano exterior, não-substancial, constitutivo de cada um. Deve-se considerar, como faz Derrida, ao ler Blanchot, que a "morte já teve lugar" (Op.cit.) quando se nasce. Não funda um princípio, nem sustenta a lógica de uma destinação, só podendo ser reconhecida no esquecimento que ela deixa. Nos traços dados a ver, pensar, escrever, e, talvez, ser.

Para Blanchot vale ressaltar o morrer como dado material do trajeto do existente, pois o que se pensa - e se representa da morte é impossível para o conhecimento (trata-se de uma realidade, enfim, incognoscível). Mas a efetividade do morrer se destitui de qualquer abstração, experimenta-se como a grande negação desviada das operações opositivas, cerceadoras de sua plena e afirmativa manifestação paradoxal.

O ser só é conhecido e autentificado na esfera apreensível do morrer. Não mais relegada ao nada, à fantasmagoria da noite (seguindo-se Hegel) - sendo, na verdade, muito mais uma fantasmagoria do dia, à contra-luz da representação da ratio como esclarecimento progressivo do sujeito -, a morte, na visão blanchotiana, afirma seu processo indivisível, singular, no intante mesmo em que se projeta como permanência, como evento desdobrado da fórmula do neutro (o il y $a$, segundo Levinas). 
Paradoxo contínuo - o materialismo hegeliano realiza-se por oposição à morte, descrevendo, porém, umaconstrução idealizada, encaminhada por um princípio negativista, que acaba por deter a dinâmica controversa da criação. Enquanto o pensamento da morte, tal como trabalhado por Blanchot, se apresenta desembaraçado de procedimentos mediados e adiados. Não compõe um princípio e um fim balizados unicamente pela negação, pois enfrenta a oposição absoluta, irrefutável, da finitude, como o risco de uma totalidade, sem síntese, experienciado no plano material da existência dada agora, sem que se suprimam as contradições produtoras da afirmação - o dizer a manifestação múltipla de vida e morte, diferenciada em cada indivíduo e, no espaço formado e desformado pela literatura, em cada autor.

Quando o crítico de "A literatura e o direito à morte" trata da poética de Ponge, ele aponta para o que contraria um sistema de pensamento e de linguagem edificado sobre a eliminição dos processos de finitude, em nome de um acabamento, de uma planificação idealizadora de processos. Dá, então, destaque ao que gera a escrita criativa e permanece como seu próprio direito de existir.

As "estranhas descrições" (BLANCHOT, 1998: 321) presentes no texto pongiano, deformador do didático e articulador do que poder-se-ia chamar de uma autopoiesis, atuam como a "própria coisa que se descreve" (Ibid.). A palavra do poeta não se erige sobre a morte das coisas - mas a partir do estado mortal generalizado pelo logos do mundo ocidental em relação ao inorgânico, ao imanifestado -, deixando de produzir o acordo com o engenho da representação disposta pelo significante de algo ausente. As descrições do poeta de Le parti pris des choses: 
começam no suposto momento em que, estando realizado o mundo, terminada a história, então quase humana a natureza, a palavra passa adiante da coisa e a coisa aprende a falar. Ponge surpreende esse momento patético em que se encontram, no limiar do mundo, a existência ainda muda e essa palavra, como sabemos, assassina da existência. (Op.cit.: 322)

Ponge deixa falar a morte (o "fundo", a terra encoberta pelo que está ausente), tudo o que expõe e desidealiza o "assassinato" verbal/racional, mantenedor do controle monosignificante da linguagem sobre as coisas. Sua escrita, montada sobre a descrição - dissecação do objeto - deixa, paradoxalmente, à mostra o processo intelectivo - a palavra clara do conceito, diria Blanchot (Ibid.) - de uma morte à vida material, apreendido no limiar das significações do mundo. Pois o poeta toma o partido das coisas, tornando-se a "vontade mediadora entre o que sobe lentamente para a palavra e a palavra que desce lentamente para a terra" (Ibid.)

Poder-se-ia afirmar que Ponge toma o partido do que é dado como ausência, presentificando-a, ao aproximar-se do engendramento conceitual dos mínimos elementos nomeáveis pela palavra, através do uso poético do descritivo. Torna-se porta-voz, entre prosa e poesia, do que não mais contém a pura figuração da linguagem: o trânsito descentralizador do sentido rumo ao inumano, ao informe e ao ilimitado, intrínsecos à qualquer idéia de ser e de nomeação.

O pólo terra expõe-se como desrepresentação do fundo encobridor da linguagem, entendida aqui como princípio e fim de tudo, como demarcação da experiência possível ao humano. Nos proemas de Ponge, fica exposta a pretensa modelação totalizante da linguagem, já que enclausurada num sistema 
biunívoco (ser/não-ser; presença/ausência) operado por um sujeito cognoscente/criador e detentor do circuito da significação, do fundamento à finalidade das coisas por ele inscritas.

É a terra que emerge, em Ponge e no itinerário exegético de Blanchot - e não o mundo, lembrando-se a clássica dicotomia filosófica, debatida por Heidegger com outros direcionamentos. E tal afirmação valerá, também, para os próximos escritos e momentos do pensador, no contato com a literatura.

Inexiste, na concepção de linguagem trabalhada, de modo mais clarificador, a partir de La part du feu, a ida ao fundo das coisas, numa busca de teor essencializante. O que importa é extrair as coisas do seu fundo ausente, morto, abstraído e metaforizado pela linguagem estética e pensante dos homens (a própria Idéia-Homem): a finitude, a terrestridade, não incorporadas ao pensamento e à produção de sentido na literatura.

O "fundo" se encontra na superfície, seria o caso de se dizer. Está aflorado, aqui, no texto que não se divide entre presença e ausência, não se deixa conformar pelo au delà da linguagem, construção metafísica feita para se desviar do complexo, diferenciador trabalho, inerente ao gesto vivo, cada vez mais ativo e afirmativo, de quem escreve, em confronto com a ordem do sentido e da linguagem: "(...)expressando, não a existência de antes do dia, mas a existência depois do dia: o mundo do fim do mundo". (Ibid.)

Ou como diz "La Terre":

Essa mistura comovente do passado de três reinos, atravessada por tudo, toda infiltrada, percorrida toda por seus germes e raízes, por suas presenças vivas: é a terra (...)

Passado, não como souvenir ou idéia, mas como matéria. 


\section{(...)}

Como se falando de História, qualquer um tomasse um punhado de terra e dissesse: "Eis tudo o que sabemos da História Universal. Mas isso nós sabemos, vêmo-la; nós a temos: bem nas mãos." (PONGE, 1999: 749)

Blanchot encontra no autor de Le Carnet du Bois de pins a atividade destituidora do sentido regulado pelos universais do conhecimento, pelas abstrações do pensamento (como diria Nietzsche), mediados que são por uma linguagem encarnada nos significados prévios do mundo, do pensamento, da história e do trabalho (lugar ou função do poeta, distribuidor de linguagem, de ritmos/conceitos, imitador de voz, para dizer com Thomas Bernhard, no interior das sociedades unaninememente mercadológicas). Encontra, também, o veio de tal atividade na filosofia nietzscheana - como evidencia o ensaio "No caminho de Nietzsche", incluído em La part du feu _, em quem a negação mostra-se capaz de destruir o legado espiritualizante do Cristianismo e eficaz na deposição extrema dos valores erguidos sob a ordem da razão (ou do eu como entidade-salvaguarda do todo), tomada como uma espécie de duplo do Deus já morto, possível de se estabilizar como construção centralizadora.

O que vai marcar, segundo o ensaísta, o corte com a representação absoluta do fundamento do mundo - Deus -, realizado por Nietzsche, é a "impossibilidade de qualquer repouso" (BLANCHOT, 1997: 278). Sob o signo da catástrofe e do dilaceramento, a história se anuncia a partir do enfrentamento das próprias forças e do trabalho mortal como constituidor das atividades criadoras, considerado como a contraposição extrema, irrecusável, "um movimento tão violento e tão tempestuoso, que a própria contradição que poderia distendê-la está excluída" (Op.cit.: 278-279). 
O tema da morte de Deus traz a inevitabilidade da destruição da ordem do mundo - e de uma certa acepção do homem - tal como valorada, idealizada pela razão e pela linguagem. Ao dizer que não "há reconciliação dos contrários" (Ibid.), mas tensão crescente, nesse embate de forças extremadas, não resolvida em síntese superior, Blanchot lê no caminhó de Nietzsche o que pode ser compreendido como chave de seu próprio trajeto pela filosofia e pela literatura. Não por acaso, é posto em realce o dado de que

a negação tentada se realiza constantemente, e o que é negado, em vez de ser rejeitado como uma possibilidade, vazia e morta, que lhe diria respeito, é, ao contrário, sentido e vivido como real (...) E assim ele [Nietzsche] chega a recomendar (...) a vontade de "tomar partido contra suas tendências", a busca em si do que é perigosamente oposto a si. (ibid.)

Ao propor o pensar contra si mesmo (Ibid.), Nietzsche marca uma leitura da filosofia e da história, distante da mera asserção niilista. Procede pelo entendimento da dinâmica paradoxal das forças que compõem a intempestiva e incessante atuação individual, entre outras e diferentes presenças, no tempo e no espaço (nesse, da literatura, para Blanchot, onde se dispõem, dentro de outra órbita, os valores, os discursos, em vigor, e o próprio campo do conhecimento).

Observável é, em Blanchot, um interesse semelhante, no que se refere à autoatribuição de tarefas inconciliáveis (Idem: 328) por que passa a literatura. A busca em si do que é perigosamente oposto a si, extraída de sua leitura de Nietzsche, conflui para o que observa - ao final de La part du feu - como a sinalização de uma ambiguidade íltima (ibid.), uma íltima vicissitude a manter "a obra em suspenso" (Ibid.). Pois a escrita 
literária sobrevive da atração "para um ponto instável em que ela pode mudar, indiferentemente, de sentido e de sinal" (Ibid.).

Esse é o risco enfrentado pela escrita de literatura - e constitutivo de sua atividade -, ao produzir um reconhecimento, uma autoatribuição, justamente pela "afirmação de todos os momentos que se opõem" (Ibid.), (na forma, inclusive, como o próprio Blanchot escreve até o fim este ensaio nuclear). Justamente pelo que incorpora do que the é exterior, do que faz marca de tensão, de morte - pelo fogo de uma intensidade, que, também, conduz ao sacrifício de ter impedida sua livre circulação por obra de tribunais, centros de juízo crítico, silêncios culturais, incêndios -, a literatura existe sob a reserva de "um ponto de instabilidade (...). "Essa instabilidade pode passar como o efeito de uma força desagregadora (...), mas essa desagregação é também construção, se subitamente por ela o desespero se faz esperança e a destruição se faz elemento de indestrutibilidade." (BLANCHOT, op. cit.: 329).

Em torno de um conjunto de textos literários produzidos sob tal risco, Maurice Blanchot dispôs a pensá-los como integrantes de um espaço de questões infindáveis sobre pensamento e criação. Textos marcados pelo fragmentário, pela morte da literatura, tal como despontada no horizonte moderno e problemático do conhecimento, e pelo trabalho de auto-posição, que significa, enfim, escrever - o ingresso nas tensões incessantes travadas no interior da cultura e no processo do tempo sob o andamento do duplo sentido inicial (idem, p. 330) que reside no "fundo" das coisas e da palavra. Deste sinal, em si duplicado e lançado como pergunta - "duplo sentido irredutível" (Ibid.) -, formulação urgente e interrompida, Blanchot não se descarta, apreendendo-o como uma prática lançada ao infinito (dos livros que estariam por vir, para fora do Livro, no extremo limite da Literatura). 
Résumé: Maurice Blanchot comprend la littérature comme un espace différentiel, paradoxal marge où le champ de la pensée est redéfini. Vie plurielle de théorie et narration, l'écriture blanchotienne établit avec des écrivains et des philosophes un entretien infini, une autre forme de lecture et de; elle conçoit un livre à venir.

\section{Referências bibliográficas}

BLANCHOT, Maurice. O espaço literário. Trad. Álvaro Cabral. Rio de Janeiro: Rocco, 1987.

BLANCHOT, Maurice A parte do fogo. Trad. Ana Maria Scherer. Rio de Janeiro: Rocco, 1997.

DERRIDA, Jacques. Demeure - Maurice Blanchot. Paris: Galilée, 1998.

HILL, Leslie. Blanchot: Extreme Contemporary. Londres e Nova York, 1997.

KOJÈVE, Alexandre. Introduction à la lecture de Hegel. Paris: Gallimard, 1947.

LEVINAS. De l'existence à l'existent. Paris: Fontaine, 1947.

PONGE, Francis. Oeuvres Complètes. Vol. 1. Paris: Gallimard, 1999. 